\title{
Acute pancreatitis in a patient receiving sitagliptin
}

\author{
Shamael Abdulredha Sanaseeri", Awsan Mohammad Almohaini, Asrar Said Hashem \\ Internal Medicine Department, Amiri Hospital, Kuwait City, Kuwait; ${ }^{*}$ Corresponding Author: drsanaseeri@yahoo.com
}

Received 10 August 2012; revised 9 September 2012; accepted 19 September 2012

\begin{abstract}
Describing a reported case of acute pancreatitis in a patient receiving sitagliptin. We present the biochemical and findings of a 60 year-old male who presented with severe abdominal pain and was found to have acute pancreatitis. This occurred one month after the commencement of sitagliptin, a dipeptidyl peptidase IV inhibitor, for the treatment of uncontrolled type 2 diabetes. Results: Pancreatic enzymes were elevated (i.e. amylase 204, lipase: 525.3) with a normal liver function test and a normal lipid profile. Ultrasound abdomen was unremarkable. In the absence of an identifiable cause for the patient's pancreatitis, sitagliptin was considered a potential trigger and on ceasing this agent, the patient recovered from his condition. Conclusion: Incretin-based therapy is an effective line in the treatment of type 2 diabetes mellitus. FDA issued a warning letters to the drug company because of emerging reports of acute pancreatitis in patients receiving sitagliptin. This is unfortunately not the first reported case of acute pancreatitis in a patient receiving sitagliptin and it supports the possibility that acute pancreatitis may be the effect of incretin-based therapy.
\end{abstract}

Keywords: Acute Pancreatitis; Dipeptidyl Peptidase IV Inhibitor; Sitagliptin

\section{INTRODUCTION}

Glucagon like peptide-1 (GLP-1) is an incretin hormone that results in glucose-dependent insulin secretion, suppression of glucagon secretion, a delay in gastric emptying, and a decrease in caloric intake likely seconddary to centrally mediated signaling [1]. The majority of known biological actions of GLP-1 depend on the presence of the two N-terminal amino acids; these are removed by the enzyme, dipeptidyl peptidase-4 (DPP-4), whose substrates are polypeptides with an alanine or a proline at the second position from the $\mathrm{N}$-terminal side [2].
DPP-4 inhibitors increase concentrations of active incretin hormones, GLP-1 and glucose-dependent insulinotropic polypeptide (secreted by the enteroendocrine L and K cells, respectively, which are substrates for DPP-4). This results in improved B-cell responsiveness to prevailing glucose concentrations and suppression of glucagon secretion [3].

Sitagliptin is an orally active, potent, and selective inhibitor of dipeptidyl peptidase IV (DPP-IV) for the treatment of type 2 diabetes.

DPP-IV inhibitors are effective in the treatment of type 2 diabetes and reducing $\mathrm{HbAlc}$ level. Although several studies have demonstrated the efficacy and safety of sitagliptin in the management of type 2 diabetes, the safety of sitaglitin is questionable.

\section{CASE REPORT}

K. A. is a 60 years old Kuwaiti gentleman, with background history of Diabetes Mellitus for the past 10 years, no complications, he is on Insulin Glargine $30 \mathrm{U}$ at bed time, Metformin 1gm trice daily, Repaglide $2 \mathrm{mg}$ trice daily, and recently started on Sitagliptin $100 \mathrm{mg}$ once daily (1 month ago). He is also Hypertensive on Lisinopril $20 \mathrm{mg}$ once daily, Dyslipidaemic on Atorvastatin 10 $\mathrm{m}$ once daily, and on Aspirin $75 \mathrm{mg}$ once daily. Follow up with his general practitioner. No previous hospital admission.

$\mathrm{He}$ is an employee, married with children, non-smoker, and non-ethanol consumer. He has no known drug allergies.

He presented to the Medical casualty with 6 days history of abdominal pain, mainly epigastric, radiating to his back, consistent, relieved with change in position, and aggravated by food ingestion. There was no history of nausea or vomiting, no diarrhea or constipation, and no fever. Other systemic review was unremarkable.

On Examination, he was conscious, alert, and oriented. His blood pressure was 130/70, heart rate was $76 \mathrm{bpm}$, respiratory rate was $20 \mathrm{bpm}, \mathrm{O}_{2}$ saturation was $97 \%$, and he was afebrile. Cardiovascular and respiratory examinations were unremarkable. Abdominal examination revealed epigastric tenderness, no organomegaly. Neurological examination was unremarkable. 
Initial laboratory investigations showed: $\mathrm{CBC}\{\mathrm{WBC}$ : 8.1, Hb: 121, PLT: 203\}, U\&E \{Glucose: 7.8, Bun: 9.7, Creat: 132, Na: 140, K: 4.2, Ca: 2.32, CO2: 27\}, LFT \{ALT: 23, AlkPhos: 51, GGT: 21, Amylase: 204, Lipase: 525.3\}, Lipid Profile \{T.Chol: 3.2, TG: 0.74, HDL: 0.97, LDL: 1.9, VLDL: 0.3$\}$, Coagulation Profile: \{PT: 16.5, INR: 1.14 , APTT: 28.2$\}$. Trop I: Negative $\times 3$. Other investigations: ECG: Normal, chest $\mathrm{x}$-ray: Normal, Ultrasound Abdomen: Unremarkable study. Urine R/M: Normal. CT Abdomen and Pelvis was done which was Normal. Colonoscopy was also Normal.

The patient was admitted to the hospital as a case of Acute Pancreatitis, in reference to his symptomatology and biochemical elevation of pancreatic enzymes (amylase and lipase). The etiology of his acute pancreatitis is believed to be drug-induced, giving the history of recent introduction of Sitagliptin. Other common causes of acute pancreatitis were excluded gall stones, no history of ethanol consumption, no hypercalcemia, and no hyperlipidemia\} Anti-Diabetic agents were held, and the patient was started on Insulin \{Glargineat bedtime, and Actrapidtrice daily\}.

During his hospital stay, the patient was improveing. His laboratory investigations were also improving $\{$ Amylase: $204 \rightarrow 117 \rightarrow 99 \rightarrow 87\}$, $\{$ Lipase: $525.3 \rightarrow 186.7 \rightarrow$ $134.7 \rightarrow 109.9 \rightarrow 96.8\}$.

The patient was discharged after 6 days, and Metformin was re-introduced together with Insulin.

\section{DISCUSSION}

In 2007 a question was raised about the causal relationship between the first of the glucagon-like peptide 1 receptor agonists, exenatide, and pancreatitis, as postmarketing reports of pancreatitis in patients treated with this agent had been received by the Food and Drug Administration (FDA). Sitagliptin entered the market about a year and a half later, and now there are similar reports of acute pancreatitis. Till 2010, 88 cases of acute pancreatitis have been reported to the FDA in patients taking sitagliptin. Of these, two cases have been hemorrhagic or necrotizing pancreatitis [4].

A number of comorbidities associated with type 2 diabetes can predispose to pancreatitis, hypertriglyceridemia, and gallbladder disease. Pancreatitis in the general population appears to be increasing in Western countries with $60 \%-80 \%$ attributed to alcohol or gallstones but at least $20 \%$ has no clear etiology. Type 2 diabetes is associated with obesity and hyperlipidemia, each of which has been considered a putative risk factor for pancreatitis [5-7].

In animal studies, use of incretin-base therapies lead to pancreatic acinar inflammation and pyknosis, increased pancreatic ductal turnover and ductal metaplasia, which may increase the risk of acute pancreatitis [8,9].

\section{CONCLUSION}

Antidiabetic therapies based on potentiation of incretin action are now widely used; however, understanding of their long-term safety remains incomplete.

\section{REFERENCES}

[1] Aggio, L.L. and Drucker, D.J. (2007) Biology of incretins: GLP-1 and GIP. Gastroenterology, 132, 213-2157.

[2] Kieffer, T.J. and Habener, J.F. (1999) Theglucagon-likepeptides. Endocrine Reviews, 20, 876-913. doi:10.1210/er.20.6.876

[3] Dalla, M.C., Bock, G., Giesler, P.D., Serra, D.B., LiguerosSaylan, M., Foley, J.E., Camilleri, M., Toffolo, G., Cobelli, C., Rizza, R.A. and Vella, A. (2009) Dipeptidyl peptidase- 4 inhibition by vildagliptin and the effect on insulin secretion and action in response to meal ingestion in type 2 diabetes. Diabetes Care, 32, 14-18. doi: $10.2337 / \mathrm{dc} 08-1512$

[4] Olansky, L. (2010) Do incretin-based therapies cause acute pancreatitis? Journal of Diabetes Science and Technology, 4, 228-229.

[5] Forsmark, C.E. and Baillie, J. (2007) AGA institute clinical practice economics committee. AGA institute governing; Board AGA institute clinical practice and economics committee; AGA institute governing board. Gastroenterology, 132, 2022-2044.

doi:10.1053/j.gastro.2007.03.065

[6] Forsmark, C.E. and Baillie, J. (2007) AGA institute clinical practice economics committee. AGA institute governing; Board AGA institute clinical practice and economics committee; AGA institute governing board. Gastroenterology, 132, 2022-2044. doi:10.1053/j.gastro.2007.03.065

[7] Field, A.E., Coakley, E.H., Must, A., Spadano, J.L., Laird, N., Dietz, W.H., Rimm, E. and Colditz, G.A. (2001) Impact of overweight on the risk of developing common chronic diseases during a 10-year period. Archives of Internal Medicine, 161, 1581-1586. doi:10.1001/archinte.161.13.1581

[8] Nachnani, J.S., Bulchandani, D.G., Nookala, A., et al. (2010) Biochemical and histological effects of exendin-4 (exenatide) on the rat pancreas. Diabetologia, 53, 153-159. doi:10.1007/s00125-009-1515-4

[9] Matveyenko, A.V., Dry, S., Cox, H.I., et al. (2009) Beneficial endocrine but adverse exocrine effects of sitagliptin in the human islet amyloid polypeptide transgenic rat model of type 2 diabetes: Interactions with metformin. Diabetes, 58, 1604-1615. doi:10.2337/db09-0058 